\title{
Reliable in Vivo Intravascular Imaging Plaque Characterisation: A Challenge Unmet
}

Anantharaman Ramasamy, ${ }^{\mathrm{a}} \mathrm{MBChB}, \mathrm{MRCP}$; Patrick W. Serruys, ${ }^{\mathrm{b}} \mathrm{MD}, \mathrm{PhD}$; Daniel A. Jones, ${ }^{\mathrm{a}, \mathrm{c}} \mathrm{MD}$, PhD; Thomas W. Johnson, ${ }^{\mathrm{d}}$ BSc (Hons), MBBS, MRCP, MD; Ryo Torii, ${ }^{\mathrm{e}} \mathrm{MSc}, \mathrm{PhD}$; Sean P. Madden $^{\mathrm{f}}, \mathrm{PhD}$; Rajiv Amersey, ${ }^{\mathrm{a}} \mathrm{MD}, \mathrm{PhD}$; Rob Krams, ${ }^{\mathrm{g}} \mathrm{PhD}$; Andreas Baumbach, ${ }^{\mathrm{a}, \mathrm{c}} \mathrm{MD}, \mathrm{PhD}$; Anthony Mathur, ${ }^{\text {a,c }}$ MD, PhD; Christos V. Bourantas, ${ }^{\text {acch }}$ MD, PhD

${ }^{a}$ Department of Cardiology, Barts Heart Centre, Barts Health NHS Trust, London, UK

${ }^{\mathrm{b}}$ International Centre for Circulatory Health, NHLI, Imperial College London, London, UK

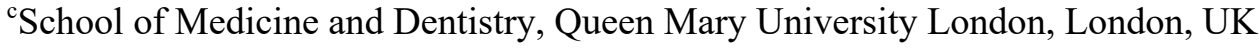

${ }^{\mathrm{d}}$ Department of Cardiology, Bristol Heart Institute, UK

${ }^{e}$ Department of Mechanical Engineering, University College London, UK

fInfraReDx, Inc., Burlington, MA, United States of America

${ }^{\mathrm{g}}$ School of Engineering and Materials Science, Queen Mary University London, London, UK

${ }^{\mathrm{h}}$ Institute of Cardiovascular Sciences, University College London, London, UK

Short title: Reliable intravascular imaging

Funding: A.R. is funded by research funds from Whipps Cross University Hospital, London. No extramural funding was used to support this work

Conflict of Interests: S.P.M is a current employee of InfraRedx. No other conflicts of interests.

\author{
*Address for correspondence \\ Christos Bourantas, $\mathrm{MD}, \mathrm{PhD}$ \\ Consultant Cardiologist, Barts Heart Centre, \\ Barts Heart Centre, West Smithfield, London EC1A 7BE \\ E-mail: cbourantas@gmail.com \\ Phone: +44 207377 7000, Fax: +44 2077919670
}




\begin{abstract}
Intravascular imaging has enabled in vivo assessment of coronary artery pathology and detection of plaque characteristics that are associated with increased vulnerability. Prospective invasive imaging studies of coronary atherosclerosis have demonstrated that invasive imaging modalities can detect lesions that are likely to progress and cause cardiovascular events and provided unique insights about atherosclerotic evolution. However, despite the undoubted value of the existing imaging techniques in clinical and research arenas, all the available modalities have significant limitations in assessing plaque characteristics when compared with histology. Hybrid/multimodality intravascular imaging appears able to overcome some of the limitations of standalone imaging, however there are only few histology studies that examined their performance in evaluating plaque patho-biology. In this article, we review the evidence about the efficacy of standalone and multi-modality/hybrid intravascular imaging in assessing plaque morphology against histology, highlight the advantages and limitations of the existing imaging techniques and discuss the future potential of emerging imaging modalities in the study of atherosclerosis.
\end{abstract}

Keywords: intravascular ultrasound; optical coherence tomography; histology; hybrid intravascular imaging; near infrared histology 


\section{Introduction}

Pathology studies have shown that the vulnerable lesions i.e., the lesions that are likely to progress and cause cardiovascular events have specific phenotypic characteristics. ${ }^{1}$ Constantinides, half a century ago, was the first who showed that acute coronary events and coronary artery thrombosis are due to the rupture of lipid-rich plaques with thin fibrous caps; while Falk et al., a few years later, demonstrated that the ruptured plaques that cause myocardial infarction are often flow limiting before their destabilization. ${ }^{2,3}$ Recent reports have shown that culprit lesions are often rich in macrophages, neovascularisation and cholesterol crystals. ${ }^{4-6}$ The above pivotal studies provided consistent evidence that the culprit lesions have specific and distinct morphological characteristics, raising hopes that if we are able to identify these features in vivo and implement focal or systematic therapies then we will be able to prevent future cardiovascular events. ${ }^{7}$

The first prospective imaging studies of coronary atherosclerosis, which examined the efficacy of intravascular ultrasound (IVUS), in detecting vulnerable plaques showed that IVUS can identify highrisk lesions, albeit with limited accuracy; a fact that, at least partially, was attributed to its limited efficacy in assessing plaque phenotype.$^{8-10}$ These findings drove research towards the design of new imaging modalities that would enable more accurate evaluation of plaque morphology and were validated against histology.

The efficacy of invasive imaging in assessing in vivo plaque morphology has been extensively discussed in several reports; ${ }^{7,11-14}$ the present review focuses on its comparison against histology. More specifically, it summarises the evidence of human histology-based studies that evaluated the efficacy and limitations of the clinically available and emerging invasive imaging techniques in detecting coronary artery pathology and discusses the potential value of multi-modality/hybrid imaging in detecting vulnerable plaque characteristics.

\section{Clinically available intravascular imaging modalities}




\section{Intravascular ultrasound}

Small-scale histology studies have showed that this modality can reliably quantify the lumen and plaque dimensions and characterise plaque composition (Supplementary table 1 ). ${ }^{15,16}$ Later reports confirmed the efficacy of IVUS in quantifying lumen and vessel wall dimensions, but cast doubts about the ability of this modality in assessing plaque morphology. This limitation reflected conventional IVUS plaque characterisation's reliance on the visual inspection of the echogenicity of the different tissue types, rather than the direct assessment of the biochemical plaque composition. To overcome this limitation a computerized image processing-based methodology, called 'echogenicity' was developed that allowed accurate quantification of the acoustic properties of different plaque types. This approach relies on the comparison of varying grey-value intensities detected in the defined plaque against the echogenicity of the adventitia which is assumed to be composed of fibrotic tissue. A porcine histology study demonstrated that this modality has a high sensitivity in detecting different tissues types; ${ }^{17}$ these findings however were not confirmed by a small human histology study which demonstrated no association between different plaque components (i.e., smooth muscle cells, collagen and calcific tissue) and echogenicity patterns. ${ }^{18}$ The above results as well as the development of automated signal processing methodologies that were able to analyse the backscattered IVUS signal to better characterise plaque composition has restricted the applications of echogenicity in the study of atherosclerosis.

Radiofrequency analysis of the intravascular ultrasound backscattered signal

Intravascular ultrasound virtual histology

Radiofrequency analysis of the IVUS backscatter signal enabled measurement of the amplitude and the frequency of the IVUS signal, providing incremental information about tissue composition and plaque morphology. IVUS virtual histology $(\mathrm{VH})$ relies on the radiofrequency analysis and processing of the backscattered IVUS signal using autoregressive models. A classification tree is then used to determine plaque composition and classify tissues to four plaque components (dense calcium, fibrotic, fibro-fatty and necrotic core) that are colour coded displayed in IVUS cross sections. The first validation study 
performed in rotational IVUS systems $(30 \mathrm{MHz})$ using histology as gold standard showed that IVUSVH was able to detect with a high accuracy all tissue types (Supplementary table 2). However, this study included a very small number of cross-sections $(\mathrm{N}=88)$ from the available data and provided a qualitative assessment of plaque type derived from IVUS-VH rather than a quantitative validation of the modality against histology. ${ }^{19}$ To address this limitation, the same group performed a more extensive validation in a larger data set, that included 115 cross sections - in these, the authors defined corresponding regions of interests (ROI, diameter: 330x330 $\mu \mathrm{m}$ ), characterised the predominant tissue type in histology and IVUS-VH in each ROI and compared the estimations of IVUS-VH and histology. An excellent agreement was noted between the estimations of IVUS-VH and histology (accuracy $>93 \%$ for detecting all tissue types and $\kappa=0.845$ ), a finding that encouraged the development of algorithms which enabled classification of plaque phenotype (i.e., adaptive intima thickening, pathological intima thickening, fibrotic, fibrocalcific, thin and thick cap fibroatheroma and calcified fibroatheroma) based on the estimations of IVUS-VH about plaque composition. ${ }^{20} \mathrm{~A}$ histology-based validation study in rabbits - with limited inclusion of plaque phenotypes ${ }^{21}$ - showed that IVUS-VH has an excellent specificity and high sensitivity in detecting plaque phenotypes, a finding that supported the design of prospective large scale studies utilising IVUS-VH to detect vulnerable plaques. ${ }^{8,10}$

However, recent reports raised concerns about the efficacy of IVUS-VH in assessing plaque composition. Two porcine histology-based studies showed that IVUS-VH is unable to accurately detect lipid component. ${ }^{17,22}$ These results have been at least partially attributed to the fact that lipid tissue in porcine models is likely to have a different composition than the lipid tissue in humans. ${ }^{23}$ Nevertheless, a recent human histology-based study confirmed the limited accuracy of IVUS-VH in assessing plaque composition with a low sensitivity (42\%) and positive predictive value (40\%) in detecting large necrotic cores. $^{24}$

There is one histology study that examined the efficacy of IVUS-VH in assessing plaque composition in data acquired by later generation with higher frequency $(45 \mathrm{MHz})$ rotational IVUS systems. ${ }^{25}$ The algorithms were trained using histology data in 511 ROIs (111 cross sections) and validated in 1060 ROIs; the authors reported a $76.7 \%$ accuracy of IVUS-VH in detecting all tissue types that increased to 
$88.6 \%$ when they excluded from the analysis ROIs portraying acoustic shadowing behind calcific tissues. The reported results are promising however more robust evidence is needed before its wider use in research.

\section{Integrated backscatter intravascular ultrasound analysis}

Integrated backscatter (IB) analysis relies on fast Fourier transformation of the frequency of the IVUS signal backscattered from a small volume of tissue. Several histology-based studies have assessed the efficacy of IB-IVUS in characterising tissue types (Supplementary table 2). In a study performed by Kawasaki et al. it was shown that IB-IVUS has a high agreement with histology in detecting plaque composition $(\kappa=0.80) .{ }^{26}$ A subsequent clinical study, performed in 140 patients, showed that plaque composition and in particular the presence of lipid tissue detected by this modality can predict lesions that are likely to progress and cause events. ${ }^{27}$ These findings attracted attention and led research to design user friendly software for the online processing of IVUS data. ${ }^{28,29}$

A recent histology study that compared IVUS-VH and IB-IVUS showed that the latter has a higher accuracy in assessing plaque components; ${ }^{30}$ however, a multi-modality imaging study conducted by the same research group comparing IB-IVUS, OCT and grayscale IVUS showed that IB-IVUS outperforms grayscale IVUS but has a lower efficacy in detecting different tissue types compared to OCT. ${ }^{31}$ These findings, as well as the fact that the technology is available only in Japan, have limited the clinical applications of this modality in the clinical and research arena.

\section{$\underline{\text { iMAP intravascular ultrasound }}$}

iMAP-IVUS involves measurement of 40 different spectral parameters using autoregressive models and their comparison with the corresponding values of a large database obtained from histopathological analysis of typical atherosclerotic plaques.

There is a single validation study comparing iMAP-IVUS with histology which showed a high level of accuracy for all tissue types (Supplementary table 2). However, there are no other reports to confirm the above findings while an in vivo study comparing iMAP-IVUS with IB-IVUS showed no correlation 
for lipid pools and a moderate correlation for the other tissue types. ${ }^{32}$ Therefore, the efficacy of iMAP in characterising plaque composition remains questionable.

\section{Optical coherence tomography}

\section{Tissue composition}

Optical Coherence Tomography (OCT) was introduced at the beginning of this century to overcome the inherent limitations of IVUS. The key advantage of OCT is its greater resolution, which is typically $12-18 \mu \mathrm{m}$; this enables more detailed assessment of the lumen and vessel wall pathology. However, superior resolution comes at a cost of limited imaging depth $(\sim 2 \mathrm{~mm})$ that often prevents complete assessment of vessel wall. The first studies examining the efficacy of OCT in assessing plaque characteristics, using histology as gold standard demonstrated its superiority against IVUS (Supplementary table 3). In the study of Yabushita $e t a l^{33}$ a high overall agreement was noted between OCT and histology for all tissue types, a finding that was confirmed by Kawasaki et $a l^{31}$ and Kume et $a l .{ }^{34}$ The latter group also demonstrated the efficacy of OCT in estimating intima-media thickness and highlighted its value in visualizing vessel wall architecture in normal vessels and detecting media and adventitia layers. ${ }^{35}$ A recent histopathological study have also shown that OCT can detect various types of coronary calcification, including calcific nodules; nevertheless in this report the number of calcific plaques and especially the calcific nodules included were too small to allow us to quantify the efficacy of OCT in differentiating coronary calcification types. ${ }^{36}$

However, more recent reports revealed limitations of OCT in detecting plaque morphology. In the study of Rieber $e a^{37}$, a moderate agreement was reported between OCT and histology for assessing plaque morphology $(\kappa=0.67)$ which was mainly limited by the lower diagnostic accuracy within the fibrous quadrants while Manfrini et $a l^{38}$ showed that OCT cannot accurately characterize deeply embedded tissues behind thick fibrous caps and differentiate the lipid from calcific component (Supplementary table 3). Recently, analysis of the attenuation and backscatter coefficients including depth-resolved approaches have been introduced to improve plaque characterisation. These methodologies may 
facilitate plaque assessment; however additional histology studies and robust evidence are required to prove their value in the study of atherosclerosis. ${ }^{39-42}$

\section{Macrophages}

The landmark study of Tearney et al was the first that demonstrated the potential value of OCT in detecting macrophage accumulations. ${ }^{43}$ The authors showed that an increased OCT signal intensity in fibrous caps, overlying fibroatheromas, was strongly associated with the macrophages' density ( $r=0.83$, $\mathrm{p}<0.0001)$. These findings were supported by a recent study which introduced a two-step algorithm that included an OCT signal intensity metric - named normalized standard deviation - and a size filter of structures imaged by OCT and enabled detection of inflamed fibrous caps with a sensitivity of $100 \%$ and specificity of $96.8 \%{ }^{44}$

However, these results were not confirmed by a larger scale histology study which examined the efficacy of OCT in detecting macrophage accumulations in the entire plaque ${ }^{45}$ In this study, the authors developed a different automated methodology to detect "bright spots" which was able to reproducibly assess pixels' intensity taking into account the location of the pixels in the plaque and their distance from the OCT catheter. Overall, only $57 \%$ of the "bright spots" corresponded to macrophages accumulation in histology; however, when analysis focused on thin cap fibroatheromas (TCFA) it was shown that the presence of "bright spots" had a high accuracy in detecting macrophages. Interestingly, in this study some macrophages appeared dark in OCT. These findings indicate that OCT may not be as accurate as it was initially believed in detecting vascular inflammation; what is more important however is that the presence of macrophages in OCT has been a predictor of worse prognosis in the CLIMA study. ${ }^{46}$

\section{Neovascularisation}

It is widely accepted that OCT enables identification of neovascularisation and has been used in several studies to study atherosclerotic evolution. ${ }^{47}$ However, the efficacy of OCT in detecting neovascularisation against histology has not been extensively studied. A case report has shown that small black holes with a diameter $50-300 \mu \mathrm{m}$ appearing in 3 consecutive OCT cross sections 
corresponded to intravascular neo-vessel formations. ${ }^{48}$ A more recent ex vivo study that included 55 plaques and used the above definition to identify neovascularisation demonstrated that time domain OCT had a $52 \%$ sensitivity and $68 \%$ specificity in detecting plaque neovascularisation. ${ }^{49}$ The limited efficacy of time domain OCT was attributed to its poor penetration depth; no study today has examined the performance of superior frequency domain OCT in identifying neovascularisation.

\section{Cholesterol crystals}

Cumulative evidence supports the role of cholesterol crystals on the natural evolution of atherosclerotic lesions and contribute to the destabilization of vulnerable plaques. ${ }^{6}$ It has been speculated that OCT can detect cholesterol crystals which appear as linear signal rich streaks. ${ }^{50}$ However, the efficacy of the modality to identify these features has not been formally examined yet.

\section{Fibrous cap thickness}

Pathological studies have shown that cap thickness over fibroatheromas is a strong predictor of plaque vulnerability; ${ }^{51,52}$ a cap thickness of $<65 \mu \mathrm{m}$ has been used, according to histology studies, to define TCFA i.e., plaques prone to rupture and cause events. Nevertheless, this cut-off has been challenged by a recent in vivo OCT study which suggested that the best cut-off for predicting plaque rupture is $<80 \mu \mathrm{m},{ }^{53}$ a discrepancy that has been attributed to tissue shrinkage during histopathological processing.

Two studies have examined the accuracy of OCT in assessing fibrous cap thickness and showed a high agreement between OCT and histology. ${ }^{54,}{ }^{55}$ However, the inter- $(13 \pm 41 \mu \mathrm{m})$ and intra-observer $(20 \pm 59 \mu \mathrm{m})$ variability between the annotations of experts was moderate in the study of Kume et al, a finding that was confirmed by a recent more extensive analysis. ${ }^{56}$ Over the last few years automated approaches and lesion assessment criteria have been introduced for more reproducible quantification of cap thickness in OCT ${ }^{57,58}$ The first results appear promising, however further research with validation using histology data are needed to confirm that these approaches enable more reliable estimation of the fibrous cap thickness and identification of TCFA. 
Other limitations of OCT is its inability to give information about the collagen content of the fibrous cap which affects cap strength and stability and the fact that OCT cannot always accurately detect lipid component especially in the presence of macrophages or calcification. ${ }^{59}$ Polarisation-sensitive optical tomography (PS-OCT) which measures birefringence has shown potential to evaluate fibrous cap and plaque composition; however there is no detailed and quantitative validation about its accuracy in differentiating tissue types. ${ }^{60}$

\section{Thrombus}

OCT is regarded as the gold standard, not only for the detection but also for the characterisation of luminal thrombus. A landmark study, performed by Kume et $a l^{61}$, that included 108 coronary artery segments from 40 human cadavers showed that red and white thrombi have different morphological characteristics in OCT: red thrombi appear as high backscattering intra-luminal masses with a signalfree shadowing behind them while white thrombi appear as signal-rich low backscattering endoluminal masses. In this study, signal intensity attenuation was able to differentiate with a sensitivity of $90 \%$ and specificity of $88 \%$ red from white thrombi.

Clinical studies have highlighted the superiority of OCT over other invasive imaging techniques in detecting destabilised plaques that caused events - i.e., plaque rupture, ${ }^{62}$ plaque erosion, ${ }^{63}$ and erupted calcific nodules - and therefore OCT is regarded today as the method of choice for assessing culprit lesions in patients admitted with a cardiovascular event (Figure 1). However, despite the broad use of

OCT in this setting, ${ }^{64,65}$ there is no robust validation studies that have examined its efficacy in detecting the cause of the event using histology as gold standard.

\section{Near infrared spectroscopy}

Near infrared spectroscopy (NIRS) is the only clinically available imaging technique that is able to assess the chemical composition of the coronary plaques. NIRS imaging relies on the principle that 
different molecules have the ability to absorb and scatter the NIR light at different degrees and various wavelengths. The spectral analysis of the reflected NIR signal appears able to provide information about plaque composition and in particular about the presence of lipid core plaques and possibly identify areas of depleted collagen in fibrous caps (Supplementary table 4). The first validation study of NIRS, performed in 126 coronary artery segments from 51 autopsy hearts, showed that NIRS could detect with high accuracy $(0.80 ; 95 \%$ CI: $0.76-0.85)$ lipid cores with circumferential extent $>60^{\circ}$ located in the superficial plaque (cap thickness $<450 \mu \mathrm{m}$ ) ${ }^{66}$ In this study, which resulted in the first Food and Drug Administration (FDA) diagnostic label claim for lipid core plaque, plaque composition from histology was correlated with the block chemogram in NIRS which displays the probability of the presence of lipid tissue in a $2 \mathrm{~mm}$ block of the coronary artery. These data were re-analysed by Kang et $a l^{67}$ who also performed IVUS imaging and focused on the efficacy of the two modalities in assessing the phenotype of the plaque. A low sensitivity (30\%) in this study was reported that was attributed to the limited efficacy of NIRS in detecting fibroatheromas with small necrotic cores, while the false positive NIRS estimations were related to the increased lipid component seen in lesions classified as pathological intimal thickening. Two more recent reports took advantage of the data collected in the study of Gardner et $a l^{66}$ to examine the efficacy of NIRS in detecting plaque morphology: in the study of Puri et $a l^{68}$ NIRS was able to detect fibroatheromas with a moderate accuracy (c-index: 0.71 ) while Inaba $e$ t $a l^{69}$ examined the efficacy of this modality in detecting TCFA - which however were only 10 in this dataset - and showed that a maximum lipid core burden index in a $4 \mathrm{~mm}$ segment $\geq 323$ was able to identify TCFA with an excellent accuracy (area under the curve, AUC: 0.84, Supplementary table 4).

A limitation of NIRS is its inability to estimate the depth of the lipid tissue from the luminal surface. To address this limitation effort has been made to assess, using NIRS, collagen content - and thus indirectly fibrous cap thickness overlying lipid tissue; a histology study performed by Madden et $a l^{70}$, in 212 coronary artery segments, showed that NIRS can differentiate, with an AUC: 0.76 (95\% CI: 0710.81), thin from thick cap fibroatheromas providing promise for the future (Figure 2). The developed methodology is currently being validated in a large scale appropriately sized histology study. 
Additional limitations of NIRS are its inability to assess lumen and plaque dimensions and quantify plaque burden. To overcome these drawbacks, fusion of IVUS and NIRS has been proposed. Several histology imaging studies provided proofs of the concept and showed that combined NIRS-IVUS imaging enables more reliable characterisation of plaque phenotype and accurate detection of high-risk plaques. In the study of Puri et $a l^{68}$ combined NIRS-IVUS imaging enabled detection of fibroatheromas with an excellent accuracy (c-statistic: 0.80 vs. 0.76 for IVUS and 0.71 for NIRS) while in the study of Inaba et $a l^{69}$ combined NIRS-IVUS allowed detection of TCFA with a higher accuracy than standalone IVUS or NIRS ( $91 \%$ vs $69 \%$ ). Today, there is a hybrid dual probe NIRS-IVUS catheter (Makoto, InfraRedx, Inc., Burlington, MA) that enables simultaneous acquisition and accurate co-registration of NIRS and IVUS signal. This system has been used in the Lipid Rich Plaque study which included 1,271 patients who had NIRS-IVUS imaging of the non-culprit vessels and showed that an increased lipid component detected by NIRS is a predictor of culprit lesions and high-risk patients. ${ }^{71}$ Further analysis of the Lipid Rich Plaque study and the results of the PROSPECT II study (NCT02171065) are expected to provide definite answers about the efficacy of NIRS-IVUS in accurately identifying high-risk plaques. $^{72}$

\section{Multimodality and hybrid intravascular imaging}

The potential of hybrid intravascular imaging and the clinical evidence supporting the use of multimodality imaging in assessing plaque morphology have already been discussed - however for most of the emerging hybrid intravascular imaging modalities there is limited human histology data to support their efficacy and additional value in evaluating plaque morphology. ${ }^{73}$

Intravascular ultrasound - optical coherence tomography

Several histology studies have demonstrated that combined IVUS-OCT imaging allows more accurate evaluation of plaque phenotype than standalone intravascular imaging (Supplementary table 5). ${ }^{55,74,75}$ Goderie $e t a l^{75}$ used the combined IVUS and OCT to study ex vivo coronary plaque characteristics in 36 cross-sectional images. The authors showed that IVUS-OCT imaging was more effective (correct 
estimations in $75 \%$ of the cases) than standalone IVUS or OCT (correct estimations in $69 \%$ and $67 \%$ of the cases respectively) in assessing coronary atheroma morphology. Fujii et al ${ }^{55}$ compared the efficacy of IVUS, OCT and their combination in detecting TCFA in 685 paired images: both modalities had a high sensitivity, specificity and positive predictive value but a low negative predictive value (19\% and $41 \%$ ) which however increased to $69 \%$ when IVUS and OCT were combined. Similarly, a more recent report that included 14 left anterior descending coronary arteries (258 5mm segments) showed that IVUS and OCT had a moderate accuracy in detecting TCFA ( $77 \%$ vs $79 \%$ ) which improved to $89 \%$ when both modalities were combined. ${ }^{74}$

Over the last few years several hybrid IVUS-OCT catheters have been designed to reliably assess plaque morphology. The first prototypes had significant limitations (i.e., bulky device, low OCT and IVUS image quality and slow image acquisition rate) which did not enable their use in the clinical arena. However, more recent revisions seem able to overcome these limitations and currently an advanced IVUS-OCT probe is FDA approved and undergoing first-in-man studies. The potential value of these catheters in assessing plaque morphology has been assessed in several histology studies that provided proof of concept, however the small number of lesions included in these reports did not allow accurate quantification of the superiority of IVUS-OCT over standalone intravascular imaging. (Figure 3). ${ }^{76,77}$

\section{Near infrared fluorescence imaging}

Near infrared fluorescence (NIRF) imaging relies on the injection of activatable markers that have the ability to bind molecules of the coronary plaques and fluoresce when they are irradiated with NIR light. For in vivo NIRF imaging - a catheter has been designed ${ }^{78}$ that recently has been combined with an IVUS (combined NIRF-IVUS) ${ }^{79}$ or an OCT probe (OCT-NIRF) ${ }^{80,81}$ Despite the fact that the combined OCT-NIRF catheter has been used in the clinical arena only in a small feasibility study ${ }^{82}$, there are robust data in animal models to support the value of NIRF in assessing plaque biology (Supplementary table 5). Experimental studies in rabbit models showed that NIRF can detect the presence of cysteine protease activity using a protease activatable agent (Prosense750), ${ }^{78}$ while indocyanine green (ICG) 
seems able to detect lipid and macrophage accumulations and areas with impaired endothelial barrier function. ${ }^{81,83}$ These findings were confirmed in pig studies, ${ }^{79,84}$ in in vitro studies in humans ${ }^{83,84}$ and in vivo in humans that were injected with ICG before undergoing carotid endarterectomy. ${ }^{85}$ Recently, new activatable markers have been designed that are able to selectively bind either macrophages ${ }^{86}$ or oxidized LDL ${ }^{87}$ and have been tested in rabbit models. In addition, there is accumulating evidence that NIRF can detect fibrin accumulation and thus more precise assessment than OCT of vessel wall healing following percutaneous coronary intervention. ${ }^{79,}{ }^{88}$ Currently, ICG is the only FDA approved NIRF agent for clinical use; however this agent binds different plaques features and thus it does not enable detection of a specific plaque characteristic. Several other NIRF agents that are currently undergoing preclinical evaluation are expected to reach the clinical arena and provide unique insight about the implications of vascular inflammation on vulnerable plaque formation.

\section{Intravascular photoacoustic imaging}

Intravascular photoacoustic imaging (IVPA) is based on the analysis of the sound produced during the thermal expansion of tissues irradiated with laser. The generated images provide complementary information about vessel wall pathology as IVUS can give information about plaque burden while IVPA appears able to assess plaque composition. ${ }^{73}$ Small scale histology studies in humans have provided proof about the efficacy of IVPA in detecting lipid component; ${ }^{89,90}$ however, these studies included a small number of segments and thus they were unable to quantitatively examine the efficacy of the modality in assessing plaque composition. Recently a large scale validation study in rabbits confirmed the efficacy of IVPA in detecting lipid tissue. ${ }^{91}$ In addition, recent experimental and animal studies have shown that IVPA can be used to detect the presence of macrophages after administration of dedicated contrast agents; $;{ }^{92}, 93$ nevertheless there is no ex vivo human data to support the role of IVPA in detecting vascular inflammation.

Time resolved fluorescence spectroscopy - fluorescence lifetime imaging microscopy 
Time resolved fluorescence spectroscopy (TRFS) relies on the computation of the time required to resolve the fluorescence emitted by molecules after these have been irradiated with light. Advances in TRFS has enabled the processing of the fluorescence signal from large surfaces - florescence lifetime imaging microscopy (FLIm) - and thus in vivo application of the technology in animal studies. Several histology studies have examined the efficacy of this technology in detecting plaque characteristics and showed that FLIm imaging allows detection and differentiation of the normal, fibrous and lipid-rich plaques. ${ }^{94}$ Limitations of this modality include the need for blood clearance, the increased time needed for image acquisition, its inability to assess the lumen and vessel wall dimensions and plaque burden and the fact that FLIm is limited only to assessment of the superficial plaque $(250 \mu \mathrm{m})$. To address these limitations efforts have been made to develop hybrid FLIm-IVUS ${ }^{95}$ and FLim-OCT ${ }^{96,} 97$ imaging catheters. A recent histology study showed that combined FLIm-IVUS allows more reliable characterization than standalone IVUS (Supplementary table 5). ${ }^{95}$ However, further technological developments are needed to reduce catheter size, increase pull-back speed and the acquisition imaging rate before FLIm-IVUS has applications in the clinical arena.

\section{Discussion - Conclusion}

Figure 4 provides a schematic representation of the existing evidence in evaluating plaque characteristics; it is apparent that the invasive imaging techniques have complementary strengths and that different modalities should be considered for the evaluation of different plaque features. The limited presence of hybrid imaging in this figure is mainly due to the fact that the emerging/hybrid imaging techniques have not yet been tested in detail against histology - thus further research is needed to examine their potential added value over standalone intravascular imaging.

Interestingly, the same trend is noted in both IVUS and OCT validation studies: the promising results and the enthusiasm coming from the first small scale studies in detecting plaque features in cadaveric human coronary arteries are attenuated by larger, more detailed, prospective and rigorous histology studies, which demonstrate deficiencies of the two modalities. In NIRS the discrepancies between the 
first and more recent histology studies are more likely to be attributed to the different objectives of these analyses. The study of Gardner et al focused on the detection of large lipid cores, which apparently can be accurately detected by the modality while the study of Puri et al and Inaba et al that analysed the same dataset focused on the efficacy of the technology in detecting specific plaque phenotypes. ${ }^{66,68,69}$

Histopathological studies can be challenging due to the tissue shrinkage, histology artefacts, movement of tissue between imaging and sectioning and the different types of flushing and fixation protocols used. Differences in the histology study design and sample size (i.e., prospective adequately powered with pre-specified endpoints studies $v s$ retrospective analysis of existing acquired data), in the selection of the data for comparison (i.e., analysis of the entire dataset $v s$ random selection of histological crosssections $v s$ selection of sections portraying atherosclerotic plaques), in the analysis of the selected data (i.e., analysis of ROIs in a cross section $v s$ cross-section $v s$ lesion level analysis), in the objectives of the study (i.e., evaluation of the performance of the modality in assessing plaque composition $v s$ plaque phenotype) and the inter- and intra-observer variability of the clinicians and the histopathologists who performed the analyses may have an impact on the reported results. ${ }^{98,99}$

Therefore, there is an unmet need to standardise the histological validation protocols and more importantly to define the pragmatic objectives of intravascular imaging in assessing plaque histopathology. NIRS, IVPA and FLIm can assess the biochemical composition of the plaque while IVPA and NIRF can evaluate plaque biology (Table 1). The combination of several intravascular imaging modalities in a single catheter has proven feasible; ${ }^{100}$ however, despite the multitude of invasive imaging techniques available, a catheter that will be able to accurately visualize all plaque characteristics associated with plaque vulnerability (i.e., lumen and plaque dimensions, necrotic core burden and lipid composition, fibrous cap composition and thickness, neovessels, cholesterol crystals, and micro-calcifications) is unlikely to be designed in the near future. In depth understanding of atherosclerotic evolution will allow the design and histological validation of multimodality imaging catheters that will focus on the detection of certain morphological and biological features that are predictors of vulnerable plaques. 
The ultimate objective of intravascular imaging should not be a flawless and complete assessment of the atheroma but accurate prediction of the lesions that will progress and cause cardiovascular events. Histology can be used to refine and improve intravascular imaging but the absolute validation of the emerging/hybrid modalities will be prospective studies of coronary atherosclerosis validating its efficacy in detecting vulnerable plaques. 


\section{References}

1. Naghavi M, Libby P, Falk E, Casscells SW, Litovsky S, Rumberger J, Badimon JJ, Stefanadis C, Moreno P, Pasterkamp G, Fayad Z, Stone PH, Waxman S, Raggi P, Madjid M, Zarrabi A, Burke A, Yuan C, Fitzgerald PJ, Siscovick DS, de Korte CL, Aikawa M, Juhani Airaksinen KE, Assmann G, Becker CR, Chesebro JH, Farb A, Galis ZS, Jackson C, Jang IK, Koenig W, Lodder RA, March K, Demirovic J, Navab M, Priori SG, Rekhter MD, Bahr R, Grundy SM, Mehran R, Colombo A, Boerwinkle E, Ballantyne C, Insull W, Jr., Schwartz RS, Vogel R, Serruys PW, Hansson GK, Faxon DP, Kaul S, Drexler H, Greenland P, Muller JE, Virmani R, Ridker PM, Zipes DP, Shah PK and Willerson JT. From vulnerable plaque to vulnerable patient: a call for new definitions and risk assessment strategies: Part I. Circulation. 2003;108:1664-72.

2. Constantinides P. Plaque fissures in human coronary thrombosis. $J$ Atheroscler Res. 1966;6:117.

3. Falk E. Plaque rupture with severe pre-existing stenosis precipitating coronary thrombosis. Characteristics of coronary atherosclerotic plaques underlying fatal occlusive thrombi. Br Heart $J$. $1983 ; 50: 127-34$.

4. Burke AP, Farb A, Malcom GT, Liang YH, Smialek J and Virmani R. Coronary risk factors and plaque morphology in men with coronary disease who died suddenly. The New England journal of medicine. 1997;336:1276-82.

5. Virmani R, Kolodgie FD, Burke AP, Finn AV, Gold HK, Tulenko TN, Wrenn SP and Narula J. Atherosclerotic plaque progression and vulnerability to rupture: angiogenesis as a source of intraplaque hemorrhage. Arterioscler Thromb Vasc Biol. 2005;25:2054-61.

6. Abela GS, Aziz K, Vedre A, Pathak DR, Talbott JD and Dejong J. Effect of cholesterol crystals on plaques and intima in arteries of patients with acute coronary and cerebrovascular syndromes. $A m J$ Cardiol. 2009;103:959-68.

7. Bourantas CV, Garcia-Garcia HM, Diletti R, Muramatsu T and Serruys PW. Early detection and invasive passivation of future culprit lesions: a future potential or an unrealistic pursuit of chimeras? Am Heart J. 2013;165:869-881 e4. 
8. Stone GW, Maehara A, Lansky AJ, de Bruyne B, Cristea E, Mintz GS, Mehran R, McPherson J, Farhat N, Marso SP, Parise H, Templin B, White R, Zhang Z, Serruys PW and Investigators P. A prospective natural-history study of coronary atherosclerosis. N Engl J Med. 2011;364:226-35.

9. Stone PH, Saito S, Takahashi S, Makita Y, Nakamura S, Kawasaki T, Takahashi A, Katsuki T, Nakamura S, Namiki A, Hirohata A, Matsumura T, Yamazaki S, Yokoi H, Tanaka S, Otsuji S, Yoshimachi F, Honye J, Harwood D, Reitman M, Coskun AU, Papafaklis MI, Feldman CL and Investigators P. Prediction of progression of coronary artery disease and clinical outcomes using vascular profiling of endothelial shear stress and arterial plaque characteristics: the PREDICTION Study. Circulation. 2012;126:172-81.

10. Calvert PA, Obaid DR, O'Sullivan M, Shapiro LM, McNab D, Densem CG, Schofield PM, Braganza D, Clarke SC, Ray KK, West NE and Bennett MR. Association between IVUS findings and adverse outcomes in patients with coronary artery disease: the VIVA (VH-IVUS in Vulnerable Atherosclerosis) Study. JACC Cardiovascular imaging. 2011;4:894-901.

11. Bourantas CV, Garcia-Garcia HM, Torii R, Zhang Y-J, Westwood M, Crake T and Serruys PW. Vulnerable plaque detection: an unrealistic quest or a feasible objective with a clinical value? Heart. 2016.

12. Kilic ID, Caiazzo G, Fabris E, Serdoz R, Abou-Sherif S, Madden S, Moreno PR, Goldstein J and Di Mario C. Near-infrared spectroscopy-intravascular ultrasound: scientific basis and clinical applications. European heart journal cardiovascular Imaging. 2015;16:1299-306.

13. Sinclair H, Bourantas C, Bagnall A, Mintz GS and Kunadian V. OCT for the identification of vulnerable plaque in acute coronary syndrome. JACC Cardiovascular imaging. 2015;8:198-209.

14. Sinclair H, Veerasamy M, Bourantas C, Egred M, Nair A, Calvert PA, Brugaletta S, Mintz GS and Kunadian V. The Role of Virtual Histology Intravascular Ultrasound in the Identification of Coronary Artery Plaque Vulnerability in Acute Coronary Syndromes. Cardiology in review. 2016;24:303-309.

15. Gussenhoven EJ, Essed CE, Lancee CT, Mastik F, Frietman P, van Egmond FC, Reiber J, Bosch H, van Urk H, Roelandt J and et al. Arterial wall characteristics determined by intravascular ultrasound imaging: an in vitro study. J Am Coll Cardiol. 1989;14:947-52. 
16. Potkin BN, Bartorelli AL, Gessert JM, Neville RF, Almagor Y, Roberts WC and Leon MB. Coronary artery imaging with intravascular high-frequency ultrasound. Circulation. 1990;81:1575-85.

17. Granada JF, Wallace-Bradley D, Win HK, Alviar CL, Builes A, Lev EI, Barrios R, Schulz DG, Raizner AE and Kaluza GL. In vivo plaque characterization using intravascular ultrasound-virtual histology in a porcine model of complex coronary lesions. Arterioscler Thromb Vasc Biol. 2007;27:38793.

18. Bruining N, Verheye S, Knaapen M, Somers P, Roelandt JR, Regar E, Heller I, de Winter S, Ligthart J, Van Langenhove G, de Feijter PJ, Serruys PW and Hamers R. Three-dimensional and quantitative analysis of atherosclerotic plaque composition by automated differential echogenicity. Catheter Cardiovasc Interv. 2007;70:968-78.

19. Nair A, Kuban BD, Tuzcu EM, Schoenhagen P, Nissen SE and Vince DG. Coronary plaque classification with intravascular ultrasound radiofrequency data analysis. Circulation. 2002;106:22006.

20. Nair A, Margolis MP, Kuban BD and Vince DG. Automated coronary plaque characterisation with intravascular ultrasound backscatter: ex vivo validation. EuroIntervention. 2007;3:113-20.

21. Van Herck J, De Meyer G, Ennekens G, Van Herck P, Herman A and Vrints C. Validation of in vivo plaque characterisation by virtual histology in a rabbit model of atherosclerosis. EuroIntervention. 2009;5:149-56.

22. Thim T, Hagensen MK, Wallace-Bradley D, Granada JF, Kaluza GL, Drouet L, Paaske WP, Botker HE and Falk E. Unreliable assessment of necrotic core by virtual histology intravascular ultrasound in porcine coronary artery disease. Circ Cardiovasc Imaging. 2010;3:384-91.

23. Stone GW and Mintz GS. Letter by Stone and Mintz regarding article, "unreliable assessment of necrotic core by virtual histology intravascular ultrasound in porcine coronary artery disease". Circ Cardiovasc Imaging. 2010;3:e4; author reply e5.

24. Brugaletta S, Cola C, Martin-Yuste V, Vilahur G, Oriol J, Padro T, Guerra JM, Borras R, Badimon L and Sabate M. Qualitative and quantitative accuracy of ultrasound-based virtual histology for detection of necrotic core in human coronary arteries. Int J Cardiovasc Imaging. 2014;30:469-76. 
25. Campos CM, Fedewa RJ, Garcia-Garcia HM, Vince DG, Margolis MP, Lemos PA, Stone GW, Serruys PW and Nair A. Ex vivo validation of $45 \mathrm{MHz}$ intravascular ultrasound backscatter tissue characterization. Eur Heart J Cardiovasc Imaging. 2015;16:1112-9.

26. Kawasaki M, Takatsu H, Noda T, Ito Y, Kunishima A, Arai M, Nishigaki K, Takemura G, Morita N, Minatoguchi S and Fujiwara H. Noninvasive quantitative tissue characterization and twodimensional color-coded map of human atherosclerotic lesions using ultrasound integrated backscatter: comparison between histology and integrated backscatter images. J Am Coll Cardiol. 2001;38:486-92.

27. Sano K, Kawasaki M, Ishihara Y, Okubo M, Tsuchiya K, Nishigaki K, Zhou X, Minatoguchi S, Fujita $\mathrm{H}$ and Fujiwara H. Assessment of vulnerable plaques causing acute coronary syndrome using integrated backscatter intravascular ultrasound. J Am Coll Cardiol. 2006;47:734-41.

28. Ohota M, Kawasaki M, Ismail TF, Hattori K, Serruys PW and Ozaki Y. A histological and clinical comparison of new and conventional integrated backscatter intravascular ultrasound (IBIVUS). Circ J. 2012;76:1678-86.

29. Okubo M, Kawasaki M, Ishihara Y, Takeyama U, Kubota T, Yamaki T, Ojio S, Nishigaki K, Takemura G, Saio M, Takami T, Minatoguchi S and Fujiwara H. Development of integrated backscatter intravascular ultrasound for tissue characterization of coronary plaques. Ultrasound Med Biol. 2008;34:655-63.

30. Okubo M, Kawasaki M, Ishihara Y, Takeyama U, Yasuda S, Kubota T, Tanaka S, Yamaki T, Ojio S, Nishigaki K, Takemura G, Saio M, Takami T, Fujiwara H and Minatoguchi S. Tissue characterization of coronary plaques: comparison of integrated backscatter intravascular ultrasound with virtual histology intravascular ultrasound. Circ J. 2008;72:1631-9.

31. Kawasaki M, Bouma BE, Bressner J, Houser SL, Nadkarni SK, MacNeill BD, Jang IK, Fujiwara H and Tearney GJ. Diagnostic accuracy of optical coherence tomography and integrated backscatter intravascular ultrasound images for tissue characterization of human coronary plaques. $J$ Am Coll Cardiol. 2006;48:81-8.

32. Yamada R, Okura H, Kume T, Neishi Y, Kawamoto T, Miyamoto Y, Imai K, Saito K, Hayashida A and Yoshida K. A comparison between $40 \mathrm{MHz}$ intravascular ultrasound iMap imaging system and integrated backscatter intravascular ultrasound. J Cardiol. 2013;61:149-54. 
33. Yabushita H, Bouma BE, Houser SL, Aretz HT, Jang IK, Schlendorf KH, Kauffman CR, Shishkov M, Kang DH, Halpern EF and Tearney GJ. Characterization of human atherosclerosis by optical coherence tomography. Circulation. 2002;106:1640-5.

34. Kume T, Akasaka T, Kawamoto T, Watanabe N, Toyota E, Neishi Y, Sukmawan R, Sadahira Y and Yoshida K. Assessment of coronary arterial plaque by optical coherence tomography. Am $J$ Cardiol. 2006;97:1172-5.

35. Kume T, Akasaka T, Kawamoto T, Watanabe N, Toyota E, Neishi Y, Sukmawan R, Sadahira Y and Yoshida K. Assessment of coronary intima--media thickness by optical coherence tomography: comparison with intravascular ultrasound. Circ J. 2005;69:903-7.

36. Saita T, Fujii K, Hao H, Imanaka T, Shibuya M, Fukunaga M, Miki K, Tamaru H, Horimatsu T, Nishimura M, Sumiyoshi A, Kawakami R, Naito Y, Kajimoto N, Hirota S and Masuyama T. Histopathological validation of optical frequency domain imaging to quantify various types of coronary calcifications. European heart journal cardiovascular Imaging. 2017;18:342-349.

37. Rieber J, Meissner O, Babaryka G, Reim S, Oswald M, Koenig A, Schiele TM, Shapiro M, Theisen K, Reiser MF, Klauss V and Hoffmann U. Diagnostic accuracy of optical coherence tomography and intravascular ultrasound for the detection and characterization of atherosclerotic plaque composition in ex-vivo coronary specimens: a comparison with histology. Coron Artery Dis. 2006;17:425-30.

38. Manfrini O, Mont E, Leone O, Arbustini E, Eusebi V, Virmani R and Bugiardini R. Sources of error and interpretation of plaque morphology by optical coherence tomography. Am J Cardiol. 2006;98:156-9.

39. Xu C, Schmitt JM, Carlier SG and Virmani R. Characterization of atherosclerosis plaques by measuring both backscattering and attenuation coefficients in optical coherence tomography. J Biomed Opt. 2008;13:034003.

40. Teo JC, Foin N, Otsuka F, Bulluck H, Fam JM, Wong P, Low FH, Leo HL, Mari JM, Joner M, Girard MJA and Virmani R. Optimization of coronary optical coherence tomography imaging using the attenuation-compensated technique: a validation study. Eur Heart J Cardiovasc Imaging. 2017;18:880887. 
41. van Soest G, Goderie T, Regar E, Koljenovic S, van Leenders GL, Gonzalo N, van Noorden S, Okamura T, Bouma BE, Tearney GJ, Oosterhuis JW, Serruys PW and van der Steen AF. Atherosclerotic tissue characterization in vivo by optical coherence tomography attenuation imaging. J Biomed Opt. 2010;15:011105.

42. Liu S, Sotomi Y, Eggermont J, Nakazawa G, Torii S, Ijichi T, Onuma Y, Serruys PW, Lelieveldt BPF and Dijkstra J. Tissue characterization with depth-resolved attenuation coefficient and backscatter term in intravascular optical coherence tomography images. J Biomed Opt. 2017;22:1-16.

43. Tearney GJ, Yabushita H, Houser SL, Aretz HT, Jang IK, Schlendorf KH, Kauffman CR, Shishkov M, Halpern EF and Bouma BE. Quantification of macrophage content in atherosclerotic plaques by optical coherence tomography. Circulation. 2003;107:113-9.

44. Di Vito L, Agozzino M, Marco V, Ricciardi A, Concardi M, Romagnoli E, Gatto L, Calogero G, Tavazzi L, Arbustini E and Prati F. Identification and quantification of macrophage presence in coronary atherosclerotic plaques by optical coherence tomography. Eur Heart J Cardiovasc Imaging. 2015;16:807-13.

45. Phipps JE, Vela D, Hoyt T, Halaney DL, Mancuso JJ, Buja LM, Asmis R, Milner TE and Feldman MD. Macrophages and intravascular OCT bright spots: a quantitative study. JACC Cardiovascular imaging. 2015;8:63-72.

46. Prati F, Romagnoli E, Gatto L, Fineschi M, Fabbiocchi F, Ozaki Y, Tamburino C, Crea F, Alfonso F and Arbustini E. Relationship between coronary plaque morphology of the left anterior descending artery and long term clinical outcome: the CLIMA study. EuroPCR. 2018;22-25 May.

47. Uemura S, Ishigami K, Soeda T, Okayama S, Sung JH, Nakagawa H, Somekawa S, Takeda Y, Kawata H, Horii $\mathrm{M}$ and Saito $\mathrm{Y}$. Thin-cap fibroatheroma and microchannel findings in optical coherence tomography correlate with subsequent progression of coronary atheromatous plaques. Eur Heart J. 2012;33:78-85.

48. Vorpahl M, Nakano M and Virmani R. Small black holes in optical frequency domain imaging matches intravascular neoangiogenesis formation in histology. Eur Heart J. 2010;31:1889.

49. Kume T, Okura H, Yamada R, Koyama T, Fukuhara K, Kawamura A, Imai K, Neishi Y and Uemura S. Detection of Plaque Neovascularization by Optical Coherence Tomography: Ex Vivo 
Feasibility Study and In Vivo Observation in Patients With Angina Pectoris. The Journal of invasive cardiology. 2016;28:17-22.

50. Tearney GJ, Regar E, Akasaka T, Adriaenssens T, Barlis P, Bezerra HG, Bouma B, Bruining N, Cho JM, Chowdhary S, Costa MA, de Silva R, Dijkstra J, Di Mario C, Dudek D, Falk E, Feldman MD, Fitzgerald P, Garcia-Garcia HM, Gonzalo N, Granada JF, Guagliumi G, Holm NR, Honda Y, Ikeno F, Kawasaki M, Kochman J, Koltowski L, Kubo T, Kume T, Kyono H, Lam CC, Lamouche G, Lee DP, Leon MB, Maehara A, Manfrini O, Mintz GS, Mizuno K, Morel MA, Nadkarni S, Okura H, Otake H, Pietrasik A, Prati F, Raber L, Radu MD, Rieber J, Riga M, Rollins A, Rosenberg M, Sirbu V, Serruys PW, Shimada K, Shinke T, Shite J, Siegel E, Sonoda S, Suter M, Takarada S, Tanaka A, Terashima M, Thim T, Uemura S, Ughi GJ, van Beusekom HM, van der Steen AF, van Es GA, van Soest G, Virmani R, Waxman S, Weissman NJ and Weisz G. Consensus standards for acquisition, measurement, and reporting of intravascular optical coherence tomography studies: a report from the International Working Group for Intravascular Optical Coherence Tomography Standardization and Validation. J Am Coll Cardiol. 2012;59:1058-72.

51. Narula J, Nakano M, Virmani R, Kolodgie FD, Petersen R, Newcomb R, Malik S, Fuster V and Finn AV. Histopathologic characteristics of atherosclerotic coronary disease and implications of the findings for the invasive and noninvasive detection of vulnerable plaques. $J$ Am Coll Cardiol. 2013;61:1041-51.

52. Tian J, Ren X, Vergallo R, Xing L, Yu H, Jia H, Soeda T, McNulty I, Hu S, Lee H, Yu B and Jang IK. Distinct morphological features of ruptured culprit plaque for acute coronary events compared to those with silent rupture and thin-cap fibroatheroma: a combined optical coherence tomography and intravascular ultrasound study. J Am Coll Cardiol. 2014;63:2209-16.

53. Yonetsu T, Kakuta T, Lee T, Takahashi K, Kawaguchi N, Yamamoto G, Koura K, Hishikari K, Iesaka Y, Fujiwara H and Isobe M. In vivo critical fibrous cap thickness for rupture-prone coronary plaques assessed by optical coherence tomography. Eur Heart J. 2011;32:1251-9.

54. Kume T, Akasaka T, Kawamoto T, Okura H, Watanabe N, Toyota E, Neishi Y, Sukmawan R, Sadahira Y and Yoshida K. Measurement of the thickness of the fibrous cap by optical coherence tomography. Am Heart J. 2006;152:755.e1-4. 
55. Fujii K, Hao H, Shibuya M, Imanaka T, Fukunaga M, Miki K, Tamaru H, Sawada H, Naito Y, Ohyanagi M, Hirota S and Masuyama T. Accuracy of OCT, grayscale IVUS, and their combination for the diagnosis of coronary TCFA: an ex vivo validation study. JACC Cardiovascular imaging. $2015 ; 8: 451-460$.

56. Radu MD, Yamaji K, Garcia-Garcia HM, Zaugg S, Taniwaki M, Koskinas KC, Serruys PW, Windecker S, Dijkstra J and Raber L. Variability in the measurement of minimum fibrous cap thickness and reproducibility of fibroatheroma classification by optical coherence tomography using manual versus semi-automatic assessment. EuroIntervention. 2016;12:e987-e997.

57. Kini AS, Vengrenyuk Y, Yoshimura T, Matsumura M, Pena J, Baber U, Moreno P, Mehran R, Maehara A, Sharma S and Narula J. Fibrous Cap Thickness by Optical Coherence Tomography In Vivo. J Am Coll Cardiol. 2017;69:644-657.

58. Bourantas CV, Serruys PW, Nakatani S, Zhang YJ, Farooq V, Diletti R, Ligthart J, Sheehy A, van Geuns RJ, McClean D, Chevalier B, Windecker S, Koolen J, Ormiston J, Whitbourn R, Rapoza R, Veldhof S, Onuma Y and Garcia-Garcia HM. Bioresorbable vascular scaffold treatment induces the formation of neointimal cap that seals the underlying plaque without compromising the luminal dimensions: a concept based on serial optical coherence tomography data. EuroIntervention. $2015 ; 11: 746-56$.

59. Di Vito L, Imola F, Gatto L, Romagnoli E, Limbruno U, Marco V, Picchi A, Micari A, Albertucci M and Prati F. Limitations of OCT in identifying and quantifying lipid components: an in vivo comparison study with IVUS-NIRS. EuroIntervention. 2017;13:303-311.

60. Nadkarni SK, Pierce MC, Park BH, de Boer JF, Whittaker P, Bouma BE, Bressner JE, Halpern E, Houser SL and Tearney GJ. Measurement of collagen and smooth muscle cell content in atherosclerotic plaques using polarization-sensitive optical coherence tomography. Journal of the American College of Cardiology. 2007;49:1474-81.

61. Kume T, Akasaka T, Kawamoto T, Ogasawara Y, Watanabe N, Toyota E, Neishi Y, Sukmawan R, Sadahira Y and Yoshida K. Assessment of coronary arterial thrombus by optical coherence tomography. Am J Cardiol. 2006;97:1713-7. 
62. Kubo T, Imanishi T, Takarada S, Kuroi A, Ueno S, Yamano T, Tanimoto T, Matsuo Y, Masho

T, Kitabata H, Tsuda K, Tomobuchi Y and Akasaka T. Assessment of culprit lesion morphology in acute myocardial infarction: ability of optical coherence tomography compared with intravascular ultrasound and coronary angioscopy. J Am Coll Cardiol. 2007;50:933-9.

63. Jia H, Abtahian F, Aguirre AD, Lee S, Chia S, Lowe H, Kato K, Yonetsu T, Vergallo R, Hu S, Tian J, Lee H, Park SJ, Jang YS, Raffel OC, Mizuno K, Uemura S, Itoh T, Kakuta T, Choi SY, Dauerman HL, Prasad A, Toma C, McNulty I, Zhang S, Yu B, Fuster V, Narula J, Virmani R and Jang IK. In vivo diagnosis of plaque erosion and calcified nodule in patients with acute coronary syndrome by intravascular optical coherence tomography. Journal of the American College of Cardiology. 2013;62:1748-58.

64. Dai J, Xing L, Jia H, Zhu Y, Zhang S, Hu S, Lin L, Ma L, Liu H, Xu M, Ren X, Yu H, Li L, Zou Y, Zhang S, Mintz GS, Hou J and Yu B. In vivo predictors of plaque erosion in patients with STsegment elevation myocardial infarction: a clinical, angiographical, and intravascular optical coherence tomography study. Eur Heart J. 2018;39:2077-2085.

65. Kobayashi N, Takano M, Tsurumi M, Shibata Y, Nishigoori S, Uchiyama S, Okazaki H, Shirakabe A, Seino Y, Hata N and Shimizu W. Features and Outcomes of Patients with Calcified Nodules at Culprit Lesions of Acute Coronary Syndrome: An Optical Coherence Tomography Study. Cardiology. 2018;139:90-100.

66. Gardner CM, Tan H, Hull EL, Lisauskas JB, Sum ST, Meese TM, Jiang C, Madden SP, Caplan JD, Burke AP, Virmani R, Goldstein J and Muller JE. Detection of lipid core coronary plaques in autopsy specimens with a novel catheter-based near-infrared spectroscopy system. JACC Cardiovascular imaging. 2008;1:638-48.

67. Kang SJ, Mintz GS, Pu J, Sum ST, Madden SP, Burke AP, Xu K, Goldstein JA, Stone GW, Muller JE, Virmani R and Maehara A. Combined IVUS and NIRS detection of fibroatheromas: histopathological validation in human coronary arteries. JACC Cardiovascular imaging. 2015;8:18494.

68. Puri R, Madder RD, Madden SP, Sum ST, Wolski K, Muller JE, Andrews J, King KL, Kataoka Y, Uno K, Kapadia SR, Tuzcu EM, Nissen SE, Virmani R, Maehara A, Mintz GS and Nicholls SJ. 
Near-Infrared Spectroscopy Enhances Intravascular Ultrasound Assessment of Vulnerable Coronary Plaque: A Combined Pathological and In Vivo Study. Arterioscler Thromb Vasc Biol. 2015;35:242331.

69. Inaba S, Mintz GS, Burke AP, Stone GW, Virmani R, Matsumura M, Parvataneni R, Puri R, Nicholls SJ and Maehara A. Intravascular Ultrasound and Near-Infrared Spectroscopic Characterization of Thin-Cap Fibroatheroma. Am J Cardiol. 2017;119:372-378.

70. Madden S, Raichlen J and Muller J. Spectroscopic detection of fibrous cap thickness overlying lipid core coronary plaques with a catheter-based near-infrared spectrospopy system. J Am Coll Cardiol. 2012;59:E-308-E308.

71. Waksman R. Assessment of coronary near-infrared spectroscopy imaging to detect vulnerable plaques and vulnerable patients. The Lipid-Rich Plaque study. Transcatheter Cardiovascular Theurapeutics. 2018;21-25 September.

72. Waksman R, Torguson R, Spad MA, Garcia-Garcia H, Ware J, Wang R, Madden S, Shah P and Muller J. The Lipid-Rich Plaque Study of vulnerable plaques and vulnerable patients: Study design and rationale. Am Heart J. 2017;192:98-104.

73. Bourantas CV, Jaffer FA, Gijsen FJ, van Soest G, Madden SP, Courtney BK, Fard AM, Tenekecioglu E, Zeng Y, van der Steen AFW, Emelianov S, Muller J, Stone PH, Marcu L, Tearney GJ and Serruys PW. Hybrid intravascular imaging: recent advances, technical considerations, and current applications in the study of plaque pathophysiology. Eur Heart J. 2017;38:400-412.

74. Brown AJ, Obaid DR, Costopoulos C, Parker RA, Calvert PA, Teng Z, Hoole SP, West NE, Goddard M and Bennett MR. Direct Comparison of Virtual-Histology Intravascular Ultrasound and Optical Coherence Tomography Imaging for Identification of Thin-Cap Fibroatheroma. Circ Cardiovasc Imaging. 2015;8:e03487.

75. Goderie TP, van Soest G, Garcia-Garcia HM, Gonzalo N, Koljenovic S, van Leenders GJ, Mastik F, Regar E, Oosterhuis JW, Serruys PW and van der Steen AF. Combined optical coherence tomography and intravascular ultrasound radio frequency data analysis for plaque characterization. Classification accuracy of human coronary plaques in vitro. Int J Cardiovasc Imaging. 2010;26:84350. 
76. Li BH, Leung AS, Soong A, Munding CE, Lee H, Thind AS, Munce NR, Wright GA, Rowsell $\mathrm{CH}$, Yang VX, Strauss BH, Foster FS and Courtney BK. Hybrid intravascular ultrasound and optical coherence tomography catheter for imaging of coronary atherosclerosis. Catheter Cardiovasc Interv. 2013;81:494-507.

77. Li J, Li X, Mohar D, Raney A, Jing J, Zhang J, Johnston A, Liang S, Ma T, Shung KK, Mahon S, Brenner M, Narula J, Zhou Q, Patel PM and Chen Z. Integrated IVUS-OCT for real-time imaging of coronary atherosclerosis. JACC Cardiovascular imaging. 2014;7:101-3.

78. Jaffer FA, Vinegoni C, John MC, Aikawa E, Gold HK, Finn AV, Ntziachristos V, Libby P and Weissleder R. Real-time catheter molecular sensing of inflammation in proteolytically active atherosclerosis. Circulation. 2008;118:1802-9.

79. Bozhko D, Osborn EA, Rosenthal A, Verjans JW, Hara T, Kellnberger S, Wissmeyer G, Ovsepian SV, McCarthy JR, Mauskapf A, Stein AF, Jaffer FA and Ntziachristos V. Quantitative intravascular biological fluorescence-ultrasound imaging of coronary and peripheral arteries in vivo. Eur Heart J Cardiovasc Imaging. 2017;18:1253-1261.

80. Yoo H, Kim JW, Shishkov M, Namati E, Morse T, Shubochkin R, McCarthy JR, Ntziachristos V, Bouma BE, Jaffer FA and Tearney GJ. Intra-arterial catheter for simultaneous microstructural and molecular imaging in vivo. Nat Med. 2011;17:1680-4.

81. Lee S, Lee MW, Cho HS, Song JW, Nam HS, Oh DJ, Park K, Oh WY, Yoo H and Kim JW. Fully integrated high-speed intravascular optical coherence tomography/near-infrared fluorescence structural/molecular imaging in vivo using a clinically available near-infrared fluorescence-emitting indocyanine green to detect inflamed lipid-rich atheromata in coronary-sized vessels. Circ Cardiovasc Interv. 2014;7:560-9.

82. Ughi GJ, Wang H, Gerbaud E, Gardecki JA, Fard AM, Hamidi E, Vacas-Jacques P, Rosenberg M, Jaffer FA and Tearney GJ. Clinical Characterization of Coronary Atherosclerosis With DualModality OCT and Near-Infrared Autofluorescence Imaging. JACC Cardiovascular imaging. 2016;9:1304-1314. 
83. Vinegoni C, Botnaru I, Aikawa E, Calfon MA, Iwamoto Y, Folco EJ, Ntziachristos V, Weissleder R, Libby P and Jaffer FA. Indocyanine green enables near-infrared fluorescence imaging of lipid-rich, inflamed atherosclerotic plaques. Sci Transl Med. 2011;3:84ra45.

84. Kim S, Lee MW, Kim TS, Song JW, Nam HS, Cho HS, Jang SJ, Ryu J, Oh DJ, Gweon DG, Park SH, Park K, Oh WY, Yoo H and Kim JW. Intracoronary dual-modal optical coherence tomography-near-infrared fluorescence structural-molecular imaging with a clinical dose of indocyanine green for the assessment of high-risk plaques and stent-associated inflammation in a beating coronary artery. Eur Heart J. 2016;37:2833-2844.

85. Verjans JW, Osborn EA, Ughi GJ, Calfon Press MA, Hamidi E, Antoniadis AP, Papafaklis MI, Conrad MF, Libby P, Stone PH, Cambria RP, Tearney GJ and Jaffer FA. Targeted Near-Infrared Fluorescence Imaging of Atherosclerosis: Clinical and Intracoronary Evaluation of Indocyanine Green. JACC Cardiovascular imaging. 2016;9:1087-1095.

86. Kim JB, Park K, Ryu J, Lee JJ, Lee MW, Cho HS, Nam HS, Park OK, Song JW, Kim TS, Oh DJ, Gweon D, Oh WY, Yoo H and Kim JW. Intravascular optical imaging of high-risk plaques in vivo by targeting macrophage mannose receptors. Sci Rep. 2016;6:22608.

87. Khamis RY, Woollard KJ, Hyde GD, Boyle JJ, Bicknell C, Chang SH, Malik TH, Hara T, Mauskapf A, Granger DW, Johnson JL, Ntziachristos V, Matthews PM, Jaffer FA and Haskard DO. Near Infrared Fluorescence (NIRF) Molecular Imaging of Oxidized LDL with an Autoantibody in Experimental Atherosclerosis. Sci Rep. 2016;6:21785.

88. Hara T, Ughi GJ, McCarthy JR, Erdem SS, Mauskapf A, Lyon SC, Fard AM, Edelman ER, Tearney GJ and Jaffer FA. Intravascular fibrin molecular imaging improves the detection of unhealed stents assessed by optical coherence tomography in vivo. Eur Heart J. 2017;38:447-455.

89. Hui J, Yu Q, Ma T, Wang P, Cao Y, Bruning RS, Qu Y, Chen Z, Zhou Q, Sturek M, Cheng JX and Chen W. High-speed intravascular photoacoustic imaging at 1.7 mum with a KTP-based OPO. Biomed Opt Express. 2015;6:4557-66.

90. Kruizinga P, van der Steen AF, de Jong N, Springeling G, Robertus JL, van der Lugt A and van Soest G. Photoacoustic imaging of carotid artery atherosclerosis. J Biomed Opt. 2014;19:110504. 
91. Zhang J, Yang S, Ji X, Zhou Q and Xing D. Characterization of lipid-rich aortic plaques by intravascular photoacoustic tomography: ex vivo and in vivo validation in a rabbit atherosclerosis model with histologic correlation. J Am Coll Cardiol. 2014;64:385-90.

92. Bui NQ, Hlaing KK, Lee YW, Kang HW and Oh J. Ex vivo detection of macrophages in atherosclerotic plaques using intravascular ultrasonic-photoacoustic imaging. Phys Med Biol. $2017 ; 62: 501-516$.

93. Keswani RK, Tian C, Peryea T, Girish G, Wang X and Rosania GR. Repositioning Clofazimine as a Macrophage-Targeting Photoacoustic Contrast Agent. Sci Rep. 2016;6:23528.

94. Marcu L. Fluorescence lifetime in cardiovascular diagnostics. J Biomed Opt. 2010;15:011106.

95. Fatakdawala H, Gorpas D, Bishop JW, Bec J, Ma D, Southard JA, Margulies KB and Marcu L. Fluorescence Lifetime Imaging Combined with Conventional Intravascular Ultrasound for Enhanced Assessment of Atherosclerotic Plaques: an Ex Vivo Study in Human Coronary Arteries. J Cardiovasc Transl Res. 2015.

96. Sherlock BE, Phipps JE, Bec J and Marcu L. Simultaneous, label-free, multispectral fluorescence lifetime imaging and optical coherence tomography using a double-clad fiber. Optics letters. 2017;42:3753-3756.

97. Lee MW, Song JW, Kang WJ, Nam HS, Kim TS, Kim S, Oh WY, Kim JW and Yoo H. Comprehensive intravascular imaging of atherosclerotic plaque in vivo using optical coherence tomography and fluorescence lifetime imaging. Scientific reports. 2018;8:14561.

98. Ford JC, O'Rourke K, Veinot JP and Walley VM. Histologic estimation of coronary artery stenoses: reproducibility and the effect of training. Cardiovasc Pathol. 2000;9:251-5.

99. Palmer ND, Northridge D, Lessells A, McDicken WN and Fox KA. In vitro analysis of coronary atheromatous lesions by intravascular ultrasound; reproducibility and histological correlation of lesion morphology. Eur Heart J. 1999;20:1701-6.

100. Bourantas CV, Tenekecioglu E, Radu M, Raber L and Serruys PW. State of the art: role of intravascular imaging in the evolution of percutaneous coronary intervention - a 30 -year review. EuroIntervention. 2017;13:644-653. 

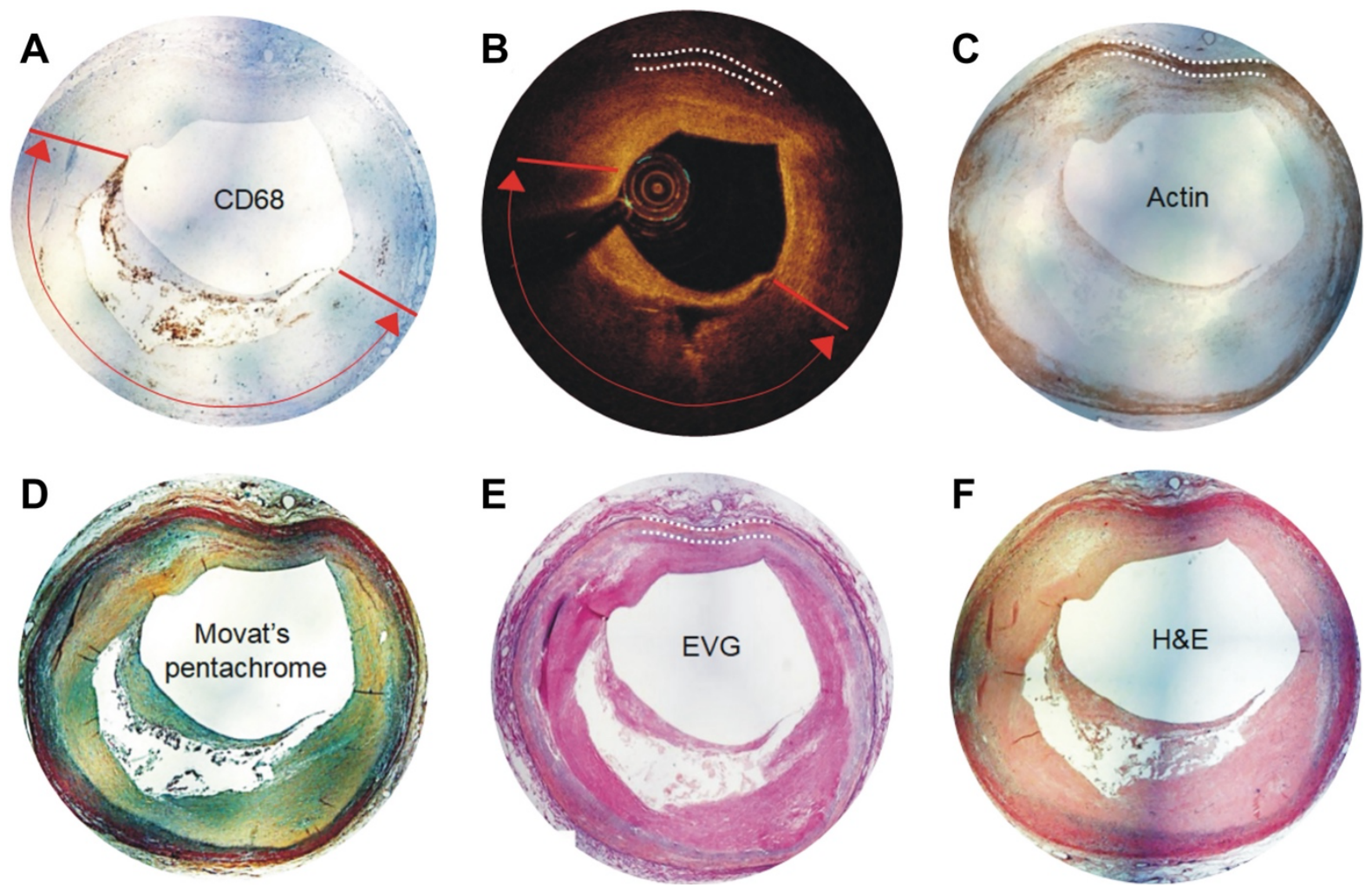

Figure 1. OCT characterisation of a complex coronary plaque. CD68 stain for CD68+ macrophage (brown stain, panel A); red arc highlights area of attenuation secondary to light absorption by macrophage and underlying necrotic core evident in matched OCT image (B). Actin stain for smooth muscle cells (panel C), demarcating medial band (only evident in OCT image for a limited arc (white dotted lines represent visible internal and external elastic membrane) due to plaque complexity. Panel D illustrates the corresponding histological cross section stained with Movat's pentachrome (red stain $=$ muscle, bright red $=$ fibrin, black $=$ nuclei, yellow $=$ collagen, blue $=$ mucin $)$; while panel E shows a histological cross section stained with Elastic Van Gieson (EVG) stain that enables detection of the elastin fibres of the internal and external elastic membrane; panel $\mathrm{F}$ portrays the histological cross section stained with Haematoxylin \& Eosin (H\&E) stain. 


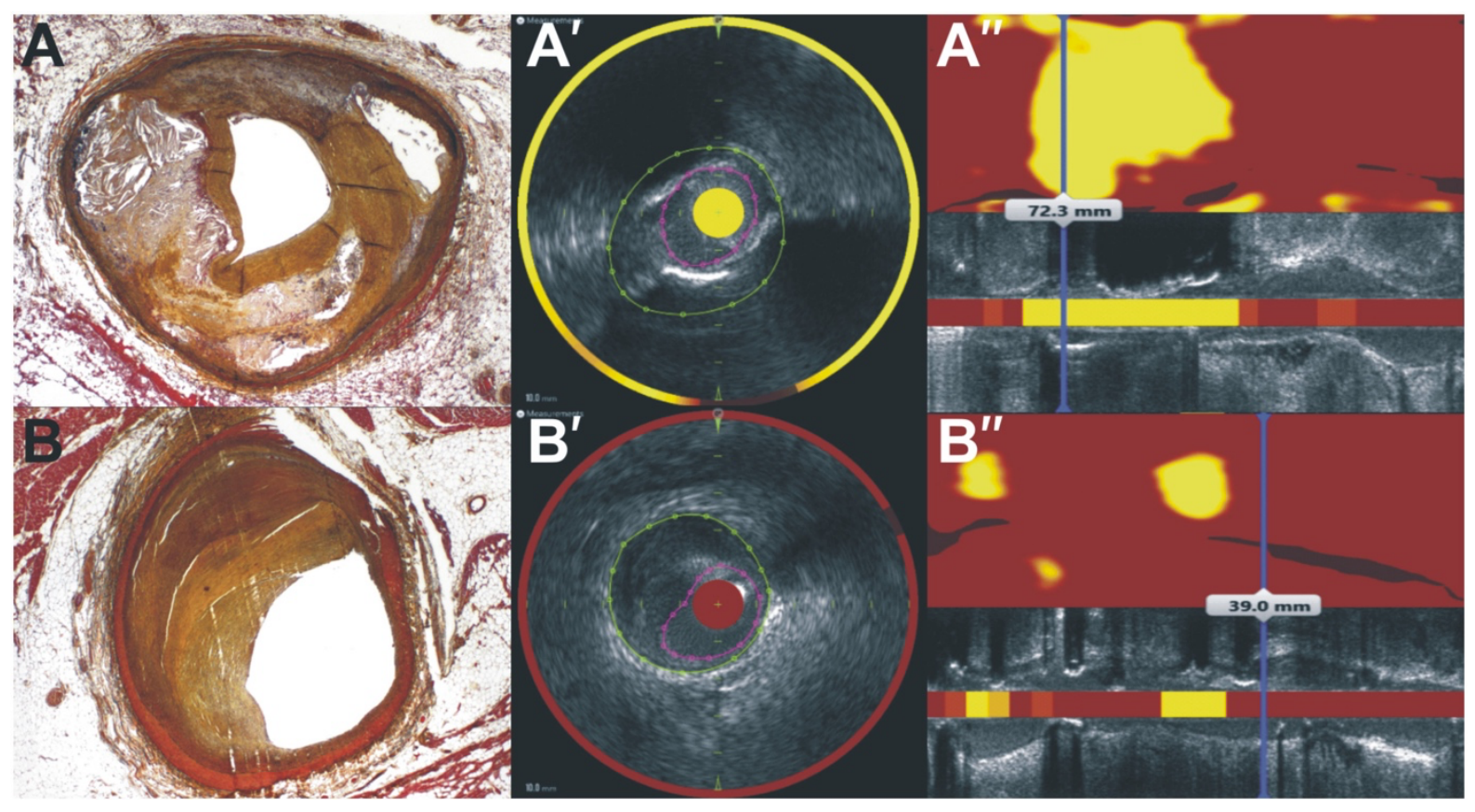

Figure 2. Combined NIRS-IVUS imaging in assessing plaque morphology. Example of a chemogram showing a very large lipid core plaque (A"), cross sectional IVUS image corresponding to $72.3 \mathrm{~mm}$ longitudinal position within the plaque and with lumen (magenta) and EEM (green) contours showing high plaque burden (A'), and Movat stained thin section confirming large circumferential lipid core with high plaque burden. Example chemogram showing two small and one medium sized lipid core plaques (B"), cross sectional IVUS image corresponding to $39.0 \mathrm{~mm}$ longitudinal position remote from the plaques and with lumen (magenta) and EEM (green) contours showing high plaque burden (B'), and Movat stained thin section confirming eccentric fibrotic plaque with high plaque burden (B). 

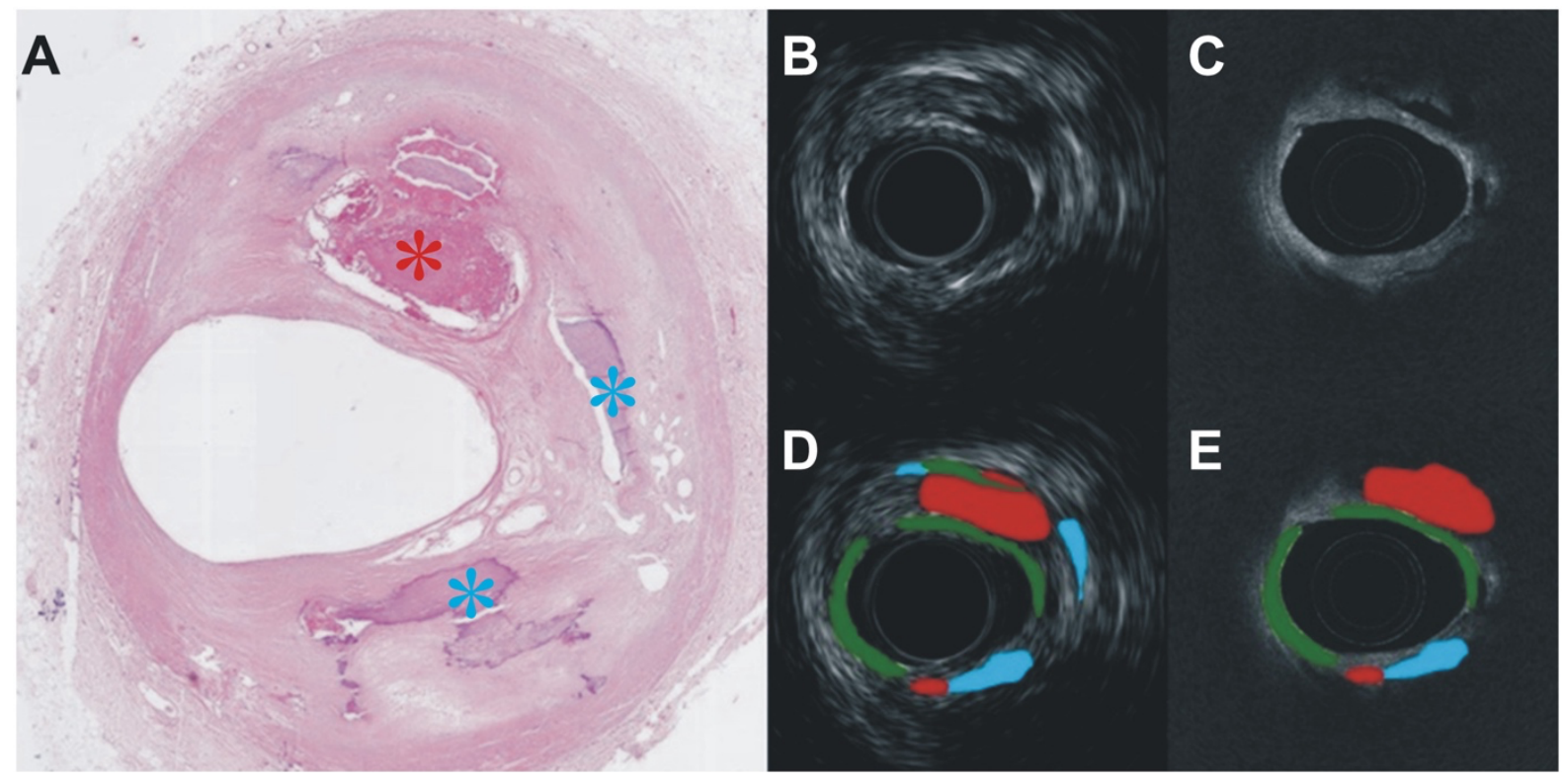

Figure 3. Output of the hybrid IVUS-OCT catheter. Histological cross section stained with Hematoxylin and Eosin stain showing a fibrocalcific plaque (calcific tissue is indicated with blue asterisks) and intraplaque haemorrhage (indicated with a red asterisk) (A). IVUS imaging (B) enables assessment of plaque burden and calcific component (indicated with blue in panel D) but it has limited efficacy in detecting the intraplaque haemorrhage (indicated with red colour) that can be identified by OCT (C, E). Images provided by Dr Brian Courtney. 


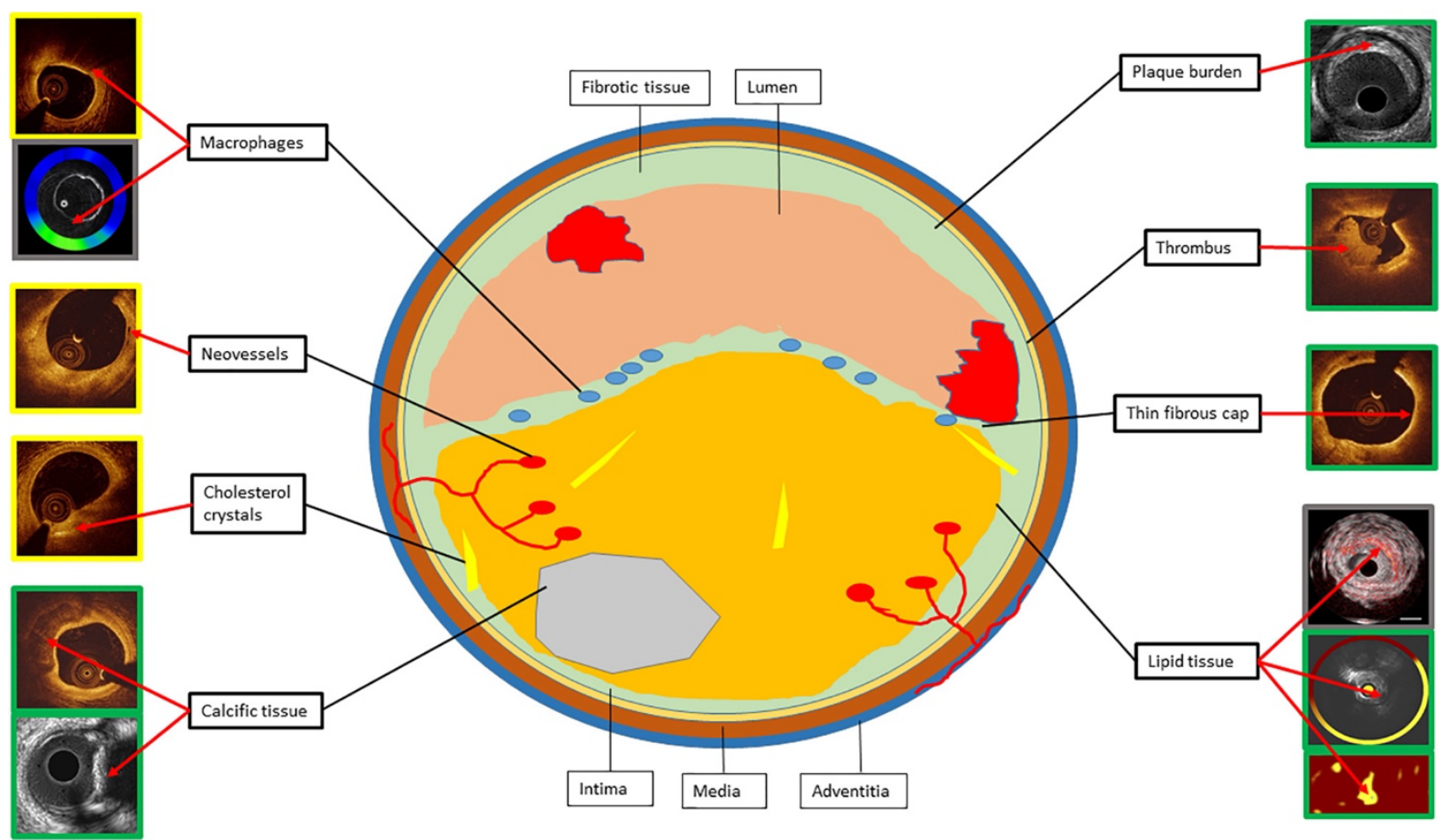

Figure 4. Role of intravascular imaging modalities in assessing plaque characteristics. The best modalities for assessing different plaque features are shown. The modality/modalities which have robust histology validation for the specific plaque features have been highlighted with a green frame, those with moderate agreement with histology are highlighted with a yellow frame and those that have not been extensively validated with a grey frame. 
Table 1: Advantages and limitations of the existing and emerging/hybrid intravascular imaging modalities in assessing plaque characteristics.

\begin{tabular}{|c|c|c|c|c|c|c|c|c|}
\hline & $\begin{array}{c}\text { Lumen } \\
\text { dimensions }\end{array}$ & $\begin{array}{l}\text { Plaque } \\
\text { burden }\end{array}$ & $\begin{array}{l}\text { Detection of } \\
\text { lipid tissue }\end{array}$ & $\begin{array}{l}\text { Detection of } \\
\text { calcific tissue }\end{array}$ & $\begin{array}{c}\text { Cap thickness } \\
\text { assessment }\end{array}$ & $\begin{array}{l}\text { Detection of } \\
\text { inflammation }\end{array}$ & $\begin{array}{c}\text { Detection of } \\
\text { neovessels }\end{array}$ & $\begin{array}{c}\text { Detection of } \\
\text { cholesterol crystals }\end{array}$ \\
\hline$I V U S$ & $\checkmark \sqrt{ } \checkmark$ & $\sqrt{ } \sqrt{ }$ & $\checkmark$ & $\checkmark \sqrt{ } \checkmark$ & $x$ & $X$ & $X$ & $x$ \\
\hline$R F-I V U S$ & $\sqrt{ } \sqrt{ }$ & $\checkmark \checkmark \checkmark$ & $\checkmark$ & $\sqrt{ } \sqrt{ }$ & $X$ & $X$ & $X$ & $X$ \\
\hline$O C T$ & $\checkmark \sqrt{ } \checkmark$ & $\checkmark \checkmark$ & $\checkmark \checkmark$ & $\checkmark \checkmark$ & $\sqrt{ } \checkmark$ & $\checkmark$ & $\checkmark$ & $\checkmark$ \\
\hline NIRS-IVUS & $\sqrt{ } \sqrt{ }$ & $\checkmark \checkmark \checkmark$ & $\sqrt{ } \sqrt{ }$ & $\checkmark \checkmark \checkmark$ & $X$ & $x$ & $x$ & $X$ \\
\hline NIRF-OCT & $\checkmark \checkmark \checkmark$ & $\sqrt{ } \checkmark$ & $\checkmark \checkmark$ & $\checkmark \checkmark$ & $\checkmark \checkmark$ & $\sqrt{ }$ & $\checkmark$ & $\checkmark$ \\
\hline IVUS-NIRF & $\sqrt{ } \sqrt{ }$ & $\checkmark \checkmark \checkmark$ & $\checkmark$ & $\sqrt{ } \checkmark \checkmark$ & $X$ & $\checkmark \checkmark$ & $\checkmark$ & $\checkmark$ \\
\hline IVPA-IVUS & $\sqrt{ } \sqrt{ }$ & $\checkmark \checkmark \checkmark$ & $\checkmark \checkmark$ & $\checkmark \checkmark \checkmark$ & $x$ & $\checkmark$ & $X$ & $x$ \\
\hline FLIm-IVUS & $\sqrt{ } \sqrt{ }$ & $\checkmark \checkmark \checkmark$ & $\checkmark \checkmark$ & $\checkmark \checkmark \checkmark$ & $\checkmark \checkmark$ & $\checkmark$ & $x$ & $X$ \\
\hline FLIm-OCT & $\checkmark \checkmark \checkmark$ & $\checkmark \checkmark$ & $\checkmark \checkmark$ & $\sqrt{ } \checkmark$ & $\checkmark \checkmark$ & $\sqrt{ }$ & $\checkmark$ & $\checkmark$ \\
\hline
\end{tabular}

Table footnote: $\checkmark \checkmark \checkmark$, excellent ability of the modality to detect the specific feature; $\sqrt{ } \checkmark$, moderate ability of the modality to detect the specific feature; $\checkmark$, weak ability of the modality to detect the specific feature; $\boldsymbol{X}$, the modality is unable to detect the specific feature.

Green coloured $\checkmark$ indicates that there is human histology data to support the efficacy of the modality in detecting the specific feature.

Pink coloured $\sqrt{ }$ indicates that there is limited or no human histology data to support the efficacy of the modality in detecting the specific featur 